\title{
The Evolution of Engagements and Social Bonds During Child-Parent Co-design
}

\author{
Jason C. Yip ${ }^{1}$, Tamara Clegg², June Ahn², Judith Odili Uchidiuno ${ }^{3}$, Elizabeth Bonsignore², \\ Austin Beck ${ }^{2}$, Daniel Pauw ${ }^{2}$, \& Kelly Mills ${ }^{2}$ \\ ${ }^{1}$ University of Washington \\ Seattle, USA \\ jcyip@uw.edu \\ ${ }^{2}$ University of Maryland \\ College Park, USA \\ \{tclegg, juneahn, ebonsign, austinbb \\ dpauw, kmills1\}@umd.edu \\ ${ }^{3}$ Carnegie Mellon University \\ Pittsburgh, USA \\ jio@andrew.cmu.edu
}

\begin{abstract}
Partnering with parents and children in the design process can be important for producing technologies that take into consideration the rich context of family life. However, to date, few studies have examined the actual process of designing with families and their children. Without understanding the process, we risk making poor design choices in user-interactive experiences that take into account important family dynamics. The purpose of this investigation is to understand how parent-child relationships in families shape co-design processes and how they are reshaped through co-design. We document the evolutionary process and outcomes that exist in co-design partnerships between researchers and families. We found that parents' engagement patterns shifted more slowly than that of children's from observing and facilitating to design partnering practices. Our analysis suggests the importance of establishing and nurturing social bonds among parents, children, and researchers in the co-design process.
\end{abstract}

\section{Author Keywords}

Participatory design; families; children; parents; co-design; methods and techniques

\section{ACM Classification Keywords}

D.2.10. Design: Methodologies

\section{INTRODUCTION}

Interviewer: What do you think about designing with the adults, like with your parents?

Amy: I think that sometimes we don't agree on things. But I think it's kind of fun because you get to bond with your parents and we get to see like what ideas are cool and like, I can design things with my family.

Permission to make digital or hard copies of all or part of this work for personal or classroom use is granted without fee provided that copies are not made or distributed for profit or commercial advantage and that copies bear this notice and the full citation on the first page. Copyrights for components of this work owned by others than the author(s) must be honored. Abstracting with credit is permitted. To copy otherwise, or republish, to post on servers or to redistribute to lists, requires prior specific permission and/or a fee. Request permissions from Permissions@acm.org.

CHI'16, May 07 - 12, 2016, San Jose, CA, USA

Copyright is held by the owner/author(s). Publication rights licensed to ACM.

ACM 978-1-4503-3362-7/16/05 ..\$15.00

DOI: http://dx.doi.org/10.1145/2858036.2858380
Interviewer: Okay. So what's an example of something you don't agree on or that you didn't agree on?

Amy: Well, like how it should look like, size, what it should have and stuff like that.

This is how one of our youth participants (Amy, age 12, pseudonym) reflected on a 10-month process of designing new learning technologies together with her father, siblings, other families, and design researchers. Her words highlight how the co-design experience involved moments of tension, but also deeper social bonding, with her father, and underscores the importance of spending time designing with her parents. Amy's reflection illuminates a ripe opportunity to more deeply understand the co-design processes of families and design researchers. HCI researchers are increasingly utilizing participatory design (PD) methodologies to develop new technologies for and with families $[19,28,29,33,57,63,64]$. While existing research has focused on the products that arise out of family co-design [30,42,57] and the co-design methods used $[33,40,63]$, a key question that HCI researchers have not fully explored is, "How do the design processes between children, parents/guardians, and researchers evolve over time, and how might we best support them?"

Without an in-depth understanding of the evolutionary process of design partnerships between researchers, children, and adults, we risk overlooking complex relationships that ultimately affect co-design work. The enormity of the parent-child relationship must be taken into consideration to deeply understand design partnerships within and across families. For instance, Darling and Steinberg [14] suggest that to better understand the socialization process of parents and children, we must differentiate between parenting practices and styles. Parental practices (e.g., discipline, affection, teaching) are specific behaviors parents enact to socialize their children, while parenting styles (i.e., authoritative, permissive, neglectful, and authoritarian) are dimensions of parental responsiveness and emotional climate in which parents raise their children $[6,14]$. Parental styles are attributed to influencing adolescent academic achievement [4,54], children's physical activity [15], children's behavior [3], and other aspects. Parental practices and styles might also 
influence the co-design process with families. For instance, in a hypothetical case, an authoritative parent may refuse to accept design ideas from their children if they do not deem the idea proper.

Parents also play an influential role in how children conceptualize technology usage. Barron et al. [5] observe that parents play several roles when it comes to learning with technology, such as project collaborators, learning brokers, resource providers, nontechnical consultants, employers, and learners. Less is known about how parental styles, parent-child relationships, and practices influence design partnerships with families. Technology today can be designed to enhance family relationships. However, if we do not understand how such design partnerships are initiated and evolve, we risk overlooking critical relational and contextual nuances of families that impact the effectiveness of technology designs for family interaction.

We address this issue by documenting an evolutionary codesign process that emerged between families and researchers, over a 10-month design-based research study [9]. In this project, we collaborated with families to design technology tools that would promote science learning between parents and children. The project is situated in a larger context of designing ubiquitous technology that includes mobile social media and tangible, community displays aimed at enhancing connected science learning in neighborhoods with children, parents, teachers, and other local stakeholders $[1,8,67]$. We explore three research questions to understand how families shape co-design processes and how family relationships are reshaped through the co-design experience.

1. How do children, parents and researchers negotiate their engagements during the design process?

2. How do children, parents, and design researchers develop relationships as they deal with productive disagreements and tensions throughout an iterative design process?

3. How do evolving engagements and relationships influence the process and perceptions of design partnerships?

In the following paper, we establish the need for understanding the evolutionary process of co-design with families, outline our design sessions, and use specific vignettes to detail several key issues that will support future design partnerships with families. Our study's contribution is to provide HCI researchers who are interested in developing design partnerships with families 1) a process overview of complex opportunities, challenges and needs encountered in family co-design; and 2) guidelines and recommendations on how best to approach design partnerships with families.

\section{BACKGROUND}

Two emergent trends of modern society are foregrounding families as an area of great importance for the HCI community. First, as technology becomes more ingrained in the lives of families, parents are more anxious about their children's adoption of new devices and software. Parents often worry about cyberbullying [16,39,53], online safety and privacy $[26,34,35,37]$, screen time and technological addiction [26,61,62], technological literacy [44], and a host of other complex issues for their children. Second, in the U.S., definitions of what constitutes a home and household are evolving rapidly. Many families deal with new configurations of family life brought on by issues of divorce, separation, and work separation [36]. Parents are now engaging in parental responsibilities at a distance using technology, such as reading at a distance [51], and using video chat for parenting [2]. Modern families in the U.S. are also changing in terms of lower marriage rates [60], immigration [45], same-sex parenting [46], and grandparents as parents [41], among other new situations. Because we can no longer design with a single-family structure in mind (i.e., the traditional nuclear family), more researchers are co-designing with families to better understand how to design suitable technologies for them.

Despite shifts in family structure and technology, parentchild interactions are highly influential on children's development. These day-to-day interactions and mediations influence school performance [10,52], social behavior [50], technology usage [26,35], and a myriad of other outcomes. As such, it is important to recognize that families often bring their parent-child interactions to the co-design process.

\section{Participatory Design With Families}

Our position is grounded in the democratic underpinnings of PD. PD research has shown that the process of developing agency is important for participant-designers, not only for pragmatic ends (e.g., techniques), but to encourage opportunities for citizenship [7,31]. PD's democratic stance underscores our efforts to offer opportunities for families to become more active co-design partners. In this paper, we apply Druin's [18] Cooperative Inquiry framework, which conceptualizes four roles that children can play in the design of new technologies: user, tester, informant, and design partner. As users, researchers observe how children engage with existing technology. As testers, children field-test prototypes of new technologies and are asked directly about their experiences. When children are informants, they engage in the design process through sharing and co-developing ideas, sketches and lowfidelity prototypes with researchers. Finally, as design partners, children work directly and equally with design researchers throughout the design process (we refer to this as co-design). We adopt Druin's framework to examine parents and children (families) as they become full design partners through the process of PD. These families have more direct contact with designers and have great influence 
at all stages of the design process, from early ideation to final designs [29].

While PD with families is not new, less is known about the process of how families can partner with design researchers on the development of new technologies. For instance, Isola and Fails [29] spotlighted a lack of HCI studies focusing on families as design partners in their comprehensive review of two major interactive design conference venues (IDC and CHI). They examined the first 9-years of the IDC conference $(2002$ - 2011) and 16-years of CHI (1995 2011). During this timeframe, Isola and Fails [29] found 84 papers they identified as related to area of technologies for families. Of the 84 papers, only 4 papers involved families as design partners (5\%): CHI - Hutchinson et al. [28] and Vetere et al. [57] and IDC - Druin et al. [19] and Kaplan and Chisik [30]. In these four papers, the families primarily tested and developed prototypes with researchers. None of these papers directly focused on examining the process of developing family design partnerships.

\section{Co-design Methods With Families}

PD methods can be defined as a collection of techniques used in conjunction with a larger design process [59]. Techniques are the activities that design partners engage in, usually generating an artifact used to communicate design ideas. Research on PD with families often focuses on individual methods and techniques. For instance, Lindquist et al. [33] worked with 50 family members and extended families in Sweden and France ranging in age from newborn to 76 years old. Their unit of analysis was the entire group of families, and their objective was to explore new methods of collaborative design, with families testing a variety of artifacts. Lindquist et al's approach focused on three techniques: cultural communication probes to inspire families to design using artifacts, family workshops to generate design ideas and relationships, and technology probes to get families to think about new technologies. Milien et al. [40] combined two PD sessions with families with interviews in family homes. They explored how individual exercises (e.g., creating posters) and family exercises (e.g., scenario and paper prototyping) can support families designing together. Similarly, Westerlund et al. [63] worked with families in Sweden and France over three years to investigate family-oriented strategies and techniques from an industrial design point of view; however, they remained agnostic about specific interactions family members had with each other.

\section{Products From Interviews and Co-design With Families}

A number of studies have developed technological designs and guidelines from contextual interviews with families. Yarosh et al. utilized interviews from parents and children (ages 7 - 13) in work-separated [65] and divorced families (children ages $7-14)$ [66] to derive design recommendations for remote parent-child communication technologies. Dalsgaard et al. relied on interviews and cultural probes with families (children ages $6-10$ ) to develop design implications for family intimacy [12] and a picture weblog [13].

Researchers have also developed new technology products through co-design partnerships with families. Hutchinson et al.'s study examined the development of technology probes, which are simple, adaptable, and flexible technologies used to gather data about in-home technology use by families, field test new technologies, and inspire families and designers to consider new technology designs. They focused on the deployment of two probes, MessageProbe and VideoProbe, among families in the USA and Europe (Sweden, France), and their goal was to develop new technologies that enable families to be active design partners in their homes. Kaplan and Chisik [30] developed a prototype for a sociable digital library book through design partnerships with children and their parents. Although these studies emphasized designing with and for families, their goal was a design product, and most did not focus on the process of children working together with their parents.

\section{Understanding the Emergent Process of Co-design With Families}

While prior studies on techniques and product development use families as design partners, much less is known about the process and perspectives of the participants. Xie et al. [64] examined three co-design sessions with older generations (i.e., grandparents) and children (ages $7-11$ ). It is one of the few studies that offers a detailed description of how children and grandparents can design together. Although Xie et al. [64] focused primarily on the design of the storytelling technology and the development of new codesign methods for families, they noted that tensions were raised in the design process between children, families, and researchers. For instance, they observed that one of the older adults felt disconnected from his grandchildren. To mitigate this issue, the research team introduced the concept of blogging and similar documenting technologies to the older adults as part of the co-design process. Overall, Xie et al. [64] found their main challenge was developing codesign methods that were comfortable for both children and older adults working together. A critical factor when trying to understand the emergent processes, relationships, and interactions between parents and children are the dynamics at play within different families. Our study extends this nascent area of research by examining a longer 10-month process in which families gathered to co-design in nine design sessions.

\section{THEORETICAL FRAMEWORKS}

Our study focuses on engagement and social activities between parents and children in the design partnership. In everyday situations, parents explicitly or tacitly interact with their children through language development help [25], discourse practices [43], technology competency [4749], and many other means. For many interactions, parents often engage as an authority and expert. However, design partnerships can disrupt these traditional engagements. 


\begin{tabular}{|c|c|c|}
\hline Family Name & Ethnic Background & Family Characteristics of Attending Co-designers \\
\hline Alexer & African-American & Mother; Father; Sons (age 8, 12) \\
\hline Boez & African-American/Caucasian & $\begin{array}{l}\text { Mother (African/African American); Father (Caucasian, does not attend } \\
\text { sessions); Daughters (both age 12) }\end{array}$ \\
\hline Caba & Latino & Mother; Daughter (age 12); Son (age 7) \\
\hline Domingo & Latino & Mother; Father; Daughters (age $8,12,13$ ) \\
\hline Estevez & Latino & Father; Mother; Daughters (age 11, 12); Son (age 8) \\
\hline Fatmia & African/African-American & Mother; Son (age 14); Son (age 9) \\
\hline Goucher & African-American & Mother; Son (age 14) \\
\hline Hiva & African/African-American & Father; Daughter (age 14); Sons (age 8, 13) \\
\hline Iguta & African-American & Son (age 13) (attends with Fatima family) \\
\hline Jaira & African/African-American & Mother; Father; Daughter (age 13) \\
\hline Lopez & Latino & Mother; Father; Son (age 14); Daughter (age 8) \\
\hline McDonald & African-American & Father; Son (age 12); Son (age 6) \\
\hline Nolan & African-American, Latina & Father (African-American); Mother (Latina); Sons (age 6, 8) \\
\hline Omar & White & Son (age 9) \\
\hline
\end{tabular}

Table 1. Demographic information of the family co-designers. All names of participants are pseudonyms.

Children can be the experts in design partnership to the same extent as adults. It is in this disruptive space we examine the evolution of co-design with families.

We also frame our analyses through the lens of sociocultural interactions [22,32]. Lave and Wenger [32] describe the formation of new interactions and identities as legitimate peripheral participation, which are small tasks that help newcomers become more experienced members in a community. Newcomers often become members of a community through simple and low-risk activities that are still important in shaping the community. As newcomers interact more closely to form social bonds and participate with experts and the community, they transform their participation. Likewise, in this study, we examine the social bonds and participation that evolve between researchers, parents, and children in co-design activities as parents and children's interactions evolve over time, as they become a part of the co-design community.

\section{METHODOLOGY}

We conducted this study using case study methods [38]. The study itself is part of a larger four-year research project to design and implement new social media technologies for science learning $[1,8,67]$. Our goal in this analysis is to understand how parents and their children engage and evolve in the process of design, as we designed new technologies with our partner families. We bound our case to design activities conducted with 14 families for a 10month period from September 2014 to July 2015.

\section{Context and Participants}

In our larger project, we are creating ubiquitous and mobile social media tools in which children and parents engage in science learning together. The social media app $[1,8,67]$ allows children to post questions, hypotheses, and inquiries about their everyday life. We are also designing large, tangible, community displays that are placed throughout the neighborhood and invite community members to interact with their posts and think about science with the children (Figure 1).

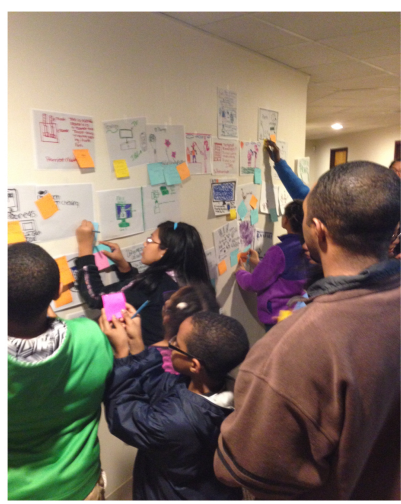

A

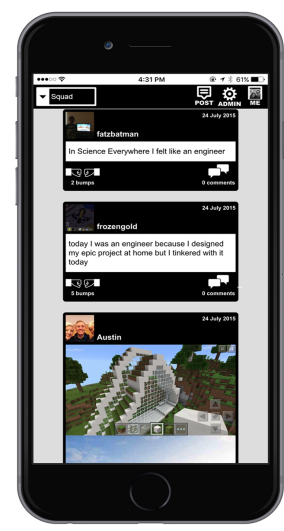

B
Figure 1. A) Children and parents designing the large interactive screen together (Meeting 4); B) The prototype app

We started our co-design efforts with families through recruitment at a local middle school back-to-school night event. We recruited 14 diverse families to participate with us on a weekly basis with two families joining later. The participants in this study consist of families and children who live in a local neighborhood in a metropolitan area in the U.S. Table 1 presents more information about the participating families and their children. We use surnames with titles (Mr., Ms.) to denote parents and given names to denote children and youth.

\section{Data Collection}

During these program sessions, the mobile application was still in the very early phases of development. Local families and children involved in the design process met at a community church that hosted our project. Because the child design partners were also participants in the informal science- learning program, we alternated between co-design sessions with families to build the new social media application, and informal science learning activities with the children. This process of both co-designing and engaging in science learning served the purpose of helping children develop expertise as both designers and subject 


\section{Session Date, Goals, and Session Description}

(1) September 2014 - To acclimate the families to both science learning and co-design partnerships; To answer the question, "What are our (youth and parents) community values?"

Description: Children and youth interviewed each other about their values. Youth then interviewed their parents between meetings.

(2) October 2014 - To identify values, resources, and challenges with a focus on science learning in the community.

Description: Families brought in photos from their neighborhood to describe their neighborhood resources, their neighbors and friends, the types of technologies used in their communities, and the places learning happens throughout their neighborhood. During the session, families (parents and children) employed a co-design technique called Big Paper [19, 23], using sticky notes to post and compile their questions and ideas on poster-size paper.

(3) October 2014 - To understand how the role of the community influences on children and their views of science.

Description: We divided the parents and youth in this session. Children and youth worked in to create posters about how science and technology are related to their everyday lives. In focus groups, parents talked about program logistics and their children's perspectives of science and math.

(4) October 2014 - To get the children to begin to design the science learning technologies. To have parents and guardians discuss more of their feelings and thoughts about family technology usage.

Description: We conducted a focus group with parents to better understand their technology usage as individuals and as families. In a separate room, children drew pictures of their technology usage and how this could relate with science learning and using large interactive screens. Children posted drawings on the wall. Families observed and posted comments on the pictures at the end.

(5) December 2014 - To know more about the rules parents place on children and their children's technology use.

Description: We used focus group techniques to ask our child design partners what technologies they used, what apps they enjoyed, what rules their parents had, and how they would like to change these rules.

(6) December 2014 - To better understand how families in this community help their children learn and use technology for learning.

Description: We presented a video to parents that was a compilation of interviews their children created about how they give and receive help learning new things, to elicit conversations on learning and technology. Parents used sticky notes and Big Paper [19, 23] to create artifacts about the roles children and parents play in learning and how technology influences these roles. At the end, the children (in small groups) showed their videos from the week before about learning.

A hiatus in co-design occurred between January to May. We took time to engage children and parents in the learning program and had them try out the initial prototype app for two months (March-May).

(7) May 2015 - After using the prototype app for two months, we observed that the older middle school children posted much less frequently than the younger children. Our observation prompted this session's goal: to find out more about how to build and design the technologies to support older youth, this design session focused on "being cool" and what makes apps popular among youth.

Description: We split the children and youth up into groups and gave them Bags-of-Stuff (a technique using an array of craft and art supplies for low-fidelity prototyping) [59] to develop what "cool" technologies look like for youth. Adult partners had to present what they learned about how to be cool with technology.

(8) July 2015 - To quickly iterate and improve on UI prototypes for the science learning app, focusing specifically on an interface for parents.

Description: We used a technique called Layered Elaboration $[58,59]$. Each team of parents and children reviewed print screenshots of specific UI design features, sketching their annotations on a transparent overlay. At the end of each round of design critiques (usually about 10 minutes long), each team shared their comments to the larger group. For each round, a new transparent overlay was added to the printed UI sheets and passed to another team for design.

(9) July 2015 -To work together with families to develop interactive community displays that could exhibit information and allow feedback from the community.

Description: We divided the families up randomly to separate parents from their children and even spouses from their partners. Each design team used Big Paper $[19,23]$ to sketch and annotate their ideas for large, ubiquitous, interactive community displays.

\section{Table 2. Design session summaries from September 2014 to July 2015}

experts - a key need that was found in prior co-design studies with children [68].

Design sessions. We adhered to the techniques of Cooperative Inquiry [17,24], a PD method emphasizing close design partnerships with children [18]. Each codesign session lasted approximately 90-minutes in the evenings (see Table 2 for design session summaries). Co- design sessions emphasized two goals. First, using contextual inquiry methods [27], we set out to understand the values of the community, as understanding values of users has been established as an important aspect in the design process of technologies and information systems in HCI [20,21]. This process included techniques to understand what families thought about their neighborhoods, science learning, rules around technology, 
and learning at home to uncover the values of the community and to understand how to best design with those values in mind.

The second goal of the sessions focused on design. The app is based on prior work done in social media technologies for science learning $[1,8,67]$, we were effectively redesigning the app with a view toward better facilitating adult-child interactions around science learning within a neighborhood ecosystem. In these sessions, both children and parents created low-tech prototypes that revealed the types of user interactions and experiences required to connect parents and children together for science learning. We photographed and video and audio recorded all design activities, including artifacts. For each of the sessions, two to four researchers conducted extensive participant observation. Each of these researchers wrote analytical memos from the design sessions to further flesh out the concepts and emerging patterns.

Interviews. At the end of the year, we conducted semistructured interviews with children $(\mathrm{n}=8)$ and parents $(\mathrm{n}=$ 5) to get their perspective of the design sessions. These children and parents participated in the summer session. Interview questions focused on feedback from the design sessions and understanding how family values of learning and community could inform the design of technologymediated, social learning experiences.

\section{Data Analysis}

To examine our data, consisting of low-tech prototypes, analytical memos, video and audio recordings, interviews, and pictures, we used a grounded theory approach with constant comparative analysis [55]. We began by examining our analytical memos, noting important aspects of the design activities as they unfolded over the year. Such aspects included when participants were motivated to participate and not participate; community values; tensions that existed between parents, children, and researchers; and outcomes of the design process for the artifacts (usability, interaction, and design ideas). Next, we transcribed interviews and the most pertinent moments of video and audio recordings for further analysis. We selected pertinent moments based on 1) points at which design partners voiced new ideas; 2) times we observed tensions between children and parents in co-design interactions; and 3) times we observed different types of engagement among design partners. We conducted another coding pass across these focused transcript excerpts to refine the codes. We triangulated these data with analytic memos, photographs, interviews, and recordings to ensure all evidence supported by at least one other data source $[11,38]$. From this, we established common patterns and emergent themes. To establish validity, we presented the data to multiple external reviewers not associated with the project to ensure best representation for each case, as well as the cases as a whole.

\section{FINDINGS}

In this section we present vignettes from our co-design sessions. We analyze each vignette based on the evolution of engagement assumed by parents and children and the development of social bonds between parents, children, and the design researchers.

\section{Meeting 2: Developing Initial Interactions and Social Bonds}

Case description. In Meeting 2, we observed that parents wanted to be supportive in co-design, but they were initially uncomfortable with the notion of co-designing with their children (or unwilling to participate). For example, Mr. Estevez sat at the table in the co-design session and used his smartphone, but did not engage in the activity directly. Speaking limited English, he responded to us mostly by nodding his head. Other parents also acted as passive observers, coming to watch and help their children in the co-design process, but did not participate actively. Family members did not always want to speak during the group discussions or spoke with one-word answers.

We also had families present their ideas for the design. Grace's parents (Jaira family) frequently helped her express her thoughts with prompting and questioning throughout the co-design sessions. Grace wrote out her thoughts on sticky notes. We noted that many of Grace's contributions were prompted from her parents, as opposed to being ideas she initiated. In contrast, another child co-designer, Bradley (son, Alexer family) had a lot of ideas to call out, but his mother wanted him to be quieter during the discussion. She took a more direct approach to make sure Bradley did not talk over people during the co-design summary time.

Engagement analysis. Parents engaged in co-design in a multitude of ways in these early meetings. Some, like Mr. Estevez and others, engaged both passively and supportively. They preferred not to contribute directly, but remained present in the meeting to show support for their children. We found that parents came so that their children could actively engage, but they were still trying to figure out what kinds of interactions to take on themselves. For instance, Ms. Fatima reflected, "Well, for me I really you know, I don't have ideas but we want the kids to grow into this (design process)." She saw herself as a "supporter" of the children's work in co-design, but explained that: "Each generation is different, even though we have experience, they know better. They are little, they know how to communicate this project to you know, to their peers." Another type of engagement that we observed among parents was that they acted as participation advocates for their own children. Grace's parents were proud of her and reported that they hoped she would be nurtured. Her parents wanted to help articulate their child's thoughts, but they had initial difficulty transitioning to design partners where they shared their own thoughts. A third type of engagement we observed was that of a parental manager. In Bradley's case, his mother managed his behavior only in the small group. 
Social bonding analysis. In these three examples, parental styles for managing child interactions affected co-design dynamics. Transitioning towards design partner engagements is not just about how researchers utilize a specific design method and technique with participants, but a shift in perceptions of how parental power dynamics take place and understanding design interactions. These initial co-design sessions with families largely worked to establish norms, social relationships, and engagements for all of our participants. All of our children and parents were newcomers to the co-design process, which differs from past studies that often document a co-design process with partners who had developed some comfort and expertise in the process already [68]. Design researchers in past studies often worked with child partners beforehand to help acclimate them to the co-design process. In this case, families were still getting to know each other and what codesign was all about.

\section{Meetings 3 and 4: Developing Engagement and Social Bonds Through Separation}

Case description. Our research team grew concerned that parents did not feel comfortable acting as full participants in the initial co-design session (e.g., not engaging, not voicing their thoughts, etc.). In subsequent sessions, we separated children and parents to increase parental comfort levels and encourage more honest dialogue about sensitive issues. In Meeting 3, during a closed adults-only session, parents began to express some concern about the co-design experience. For instance, they did not want the sessions to be more than once per week, fearing that co-design activities could detract from their children's schoolwork. Families made large sacrifices to come and work with design researchers. Additionally, in Meeting 4, parents identified monitoring online safety as a technological concern. Ms. Jaira explained how her young daughter accidentally stumbled onto pornography and could not stop the popups from occurring in the browser. In contrast, Ms. Boez felt that her children should not be monitored too closely: "You have to create a climate where they trust you, and they can come to talk to you freely. No pressure, no judgment, just listening and then lead them to bring their own conclusion, to educate them. In this situation, you did this way." However, Ms. Jaira's bad experience with pornography led her to conclude that monitoring was the best way to deal with technologies.

Engagement analysis. When separated from their children and conversing with other concerned adult family members in their community, parents engaged differently. They began to act as informants, telling us more about their homes, neighborhood, opinions, fears and worries, and philosophies in parenting. Interestingly, parents informed us of their own concerns about the design sessions and commitment level. By switching to separate focus groups, parents were able to engage in a way that could provide more sensitive information about family life and perspectives.
Social bonds analysis. When we separated parents and children, we found that parents interacted with each other more, and talked more comfortably. Interestingly, some parents voiced surprise at the split because they thought the co-design sessions were about supporting their children. By separating the parents and children, we could encourage more dialogue from parents, and we began to develop an atmosphere where parents felt more comfortable voicing honest thoughts around our co-design activities. We also noted that the increasingly sincere and open dialogue between parents promoted and strengthened their social bonds to the community. Because family interactions are so personal, yet different, we realized we needed to create conditions that engendered safe and open discussions about technology usage.

\section{Meeting 4: Designing Together}

Case description. In Meeting 4, while parents met separately, we invited our child co-designers to post drawings of technologies capturing science activities onto poster paper. Their pictures included children taking photos of themselves with a tablet or smartphone ("selfies"), children engaging in scientific investigations, and children's perspectives of the relationship between technology and science. We then asked the children to arrange their posters on the walls, to simulate a potential, tangible, community display. After the parental focus group in Meeting 4, the children and adults regrouped together to post notes about their thoughts on the posters. Parents offered design ideas, such as sharing these screens with family back home in Africa (Ms. Fatima), and printing different posts from an iPad ${ }^{\mathrm{TM}}$ (Mr. Hiva). Some parents, however, still did not want to participate actively. We observed Mr. Domingo standing by the restroom, quietly observing everyone. We encouraged him to come look at the drawings, but he was hesitant. His daughter, Carly was also standing nearby. We asked her to show the poster to her father and she hesitated at first, but then took him to the poster. However, we still could not get Mr. Domingo to fully engage; his priority was for his children to participate.

Engagement analysis. We noticed a subtle shift in parental interactions in Meeting 4's design session. Children still engaged as design-partners; they spent most of the session generating design ideas. Some parents continued to provide positive reinforcement for their children, critiquing the design posters (e.g., stating how nice they were). A transition took place here as other parents slowly acted as designers, participating more actively and offering new design and development ideas. Still, others continued to engage as supportive parents who remained present, but did not actively participate in the design process. This observation does not disparage such parents, who demonstrated their support by bringing their children to design sessions and staying at the sessions themselves. It appeared that some parents did not know yet how to promote their own ideas. For instance, Mr. McDonald noted this tension with promoting his own design ideas: 
"Sometimes I think when we are adults, we don't grab ideas and run with them. You know, we don't play with it and the kids...They were playing with it, but it was also beneficial."

Social bonds analysis. The development of social bonds was different among the parents, depending on how acclimated they were to our active co-design culture. In this vignette, most parents limited themselves to a commentary level in our design process. Although parents had begun to develop stronger social bonds through separate discussion, they had not attained a level of comfort with their design partner role to interact on equal footing with their children in our design task.

\section{Meeting 6: Engaging Deeply With Conflicting Values and Viewpoints}

Case description. In Meeting 6, children and parents openly voiced differing perspectives about how they interacted around homework and technology. Many of the children said that they often had to teach their parents the lesson before they could receive help with homework. Some parents interpreted their children's comments as a reflection of their own knowledge deficit in a subject area, or their uncertainty in how topics are taught (i.e., formal school pedagogy). In both cases, they confessed they had difficulties helping their children. Other children noted that parents did not always have the time to help and several children shared that their parents were not always able to help them with homework because when they came home after a long work day, they were too tired to help or were distracted by their own technologies. This conflict in values became a key topic of discussion amongst the parents once they gathered together in separate small groups to create posters. Ms. Jaira was especially reflective. She was concerned about the children's opinions regarding a lack of parental help, concluding that she should help her daughter more. Mr. Alexer shared that it was insightful for him to hear the children's perspectives. He thought it was very important to hear how children received and perceived help because parents often do not hear that perspective.

Engagement analysis. In this session, we observed that children acted as informants, but with a focus on critique. Our youth participants did not hesitate to explain how difficult it was to receive homework help from their parents. They also noted that they were often the expert at the most innovative technologies. For example, in reflections on the design process, the children noted that they had to explain various technologies to their parents. Moses (son, Fatima family) noted in his reflection interview, "For me it was like frustrating because it took me like a long time to explain. I had to explain everything (about technology usage). I like did it so she can...like if it was something simple." In contrast, parents interacted more reflectively. For these sessions, we observed our parents open up about their conflicting viewpoints and use this knowledge to stimulate co-design sessions. None of the parents were angry at their children's opinions; rather, they indicated that it helped them to see what other parents experienced at this intersection of technology and learning.

Social bonds analysis. To develop and strengthen social bonds with each other as design partners, parents needed time together to see each other's parenting struggles. They continued to ask each other questions about their frustrations. Ms. Boez indicated to us that it was good to interact with other parents around these issues in learning and technology together. In sharing their struggles, parents gained deeper trust and strengthened social relationships, thus activating and enhancing their engagements as design partners.

\section{Meeting 8: Parents Working Together With Their Children}

Case description. In Meeting 8, parents and children worked together with the design researchers, using Layered Elaboration [23] to mark up their design ideas on printed user interface screenshots (see Table 2 for description). However, when we assigned the parents and children into random groups, most families decided to stay with each other (parent/child). Tina (facilitator) frequently called out in this design session, "We want ideas from everybody!". A number of the parents and children generated design ideas on the visual appearance of the social media app. In one group, Amy (daughter, Estevez family) added a help button for her parents on the app. As Tina asked for more detail on this help button, Ms. Caba volunteered additional thoughts, elaborating on her daughter's design. Similarly, Justin (son, Estevez family) raised the idea of a button for sharing content with parents. Ms. Fatima independently elaborated on another idea Justin had for adding facial expressions as part of a messaging system. Interestingly, Justin is not Ms. Fatima's son, but she helped to elaborate his ideas.

Engagement analysis. We noticed that some parents became more comfortable working as full co-design partners. For many of the groups, both parents and the children came together to co-design the app. Instead of acting passively in the design process, we observed that parents became more active in interjecting ideas. Parents interacted as elaborators for both children and other parents. In another combined group, Mr. McDonald explained what his group wanted to integrate for parents (e.g., spell check, filter button that separates children and parents' posts, parent attribution). Mr. McDonald consulted with Mr. Alexer about another idea suggestion on identifications for parental posts. Mr. Alexer took the next part of the conversation explaining what parental post identifiers would look like (e.g., "parent posts could be different colors or something like that") and the need for filtering them. For children, the process of co-design with their parents became less awkward. Moses stated that overall it was still good to design with the parents because, "Like they (adults) had ideas that we normally wouldn't think about." Andy (Omar family) also explained this duality, "Well, it's fun and its kind of difficult 'cause 
sometimes they don't know how to do it or... that's why you have to teach them (about the technology)." Interestingly, Andy's opinion referred to other adults (he came without his own parents). Overall, children and youth noted it was "fun" to work together with their parents and other adults.

Social bonds analysis. We considered Meeting 8, which occurred 10 months after our initial co-design session, as a breakthrough in social bonds development. By this time, our families had not only developed closer bonds with each other, but also with the researchers. Although the Layered Elaboration design technique was new for the families, and can be a challenging technique for novice designers [68], the underlying foundational social bonds were present, which enabled parents and children to collaborate more effectively as co-design partners.

\section{Meeting 9. Families Working Together With Other Families}

Case description. In Meeting 9, we split parents and children into random groups (parents working together with other families' children), inviting them to co-design the community's interactive public tangible screen. Families seemed to be more comfortable with the grouping assignments, whereas in the previous session parents and children largely kept within their own family unit. Interestingly, adults working with others' children did not actively present or share their ideas directly, but encouraged the children to speak out more. In all five family groups, children actively called out their design ideas, but none of the parents volunteered. This is not to say parents were not directly involved in the design partnership. The children's presentations included many ideas from parents.

Engagement analysis. It was interesting to note that as we grouped parents with others' children, they again receded from public participation, and acted as facilitators. Parents encouraged children to participate and share ideas, and prompted them to elaborate. Parents were also more concerned that all of the children had opportunities to present their ideas, perhaps as a way to show their parent peers that they were supporting their children, and promoting equal participation. When Tina (facilitator) started to wrap up the design activity before her group had a chance to present, Ms. Alexer came up to Tina (facilitator) and requested that Tommy (son, McDonald family) get a chance to present. Here, Ms. Alexer began to advocate for wanting children to have positive experiences in design partnerships, even though Tommy was not her own child. In these two examples, parents started to shift towards project collaborator interactions [5], helping all of the children design and gain learning experience.

Social bonds analysis. Community social bonding took place as parents began to look out for others' children in the design-process. In this session, parents worked more with other children, not their own. We believe that stronger social bonds were developing in which families could come together in community-driven design partnerships, rather than just developing relationships within their own families. Overall, this meeting was a culminating evolution of almost one-year of engagement negotiation and social bonding.

\section{DISCUSSION}

Throughout this study, we learned a great deal about the process of co-designing with children, parents, and design researchers. Our main challenge was finding structures and mechanisms that helped parents and children negotiate interactions and develop social bonds both between themselves and with researchers. Simply put, creating a codesign process where all parents and children act as design partners takes time.

\section{Changing Engagements and Social Bonds in Parents and Children}

Co-design partnerships with families can be a slow transitional process of evolving engagements and establishing social bonds. During the early stages of this codesign process, parents relied on what they knew best as parents. Although most of the children quickly acted as a design partner [18], we observed parents enacting multifaceted interactions, from passive observer and parental manager to full design partner. This is not unusual behavior; parents often need to act as managers and facilitators of their children's activities in many contexts to support their children's developmental goals [14]. But design partnerships with parents and children demand a shift in authoritative interactions between adults and children [18]. The interactions that parents play in other contexts may or may not translate well in design partnerships. Towards the end of our 10-month evolutionary process, parents engaged more actively in design: elaborating, informing, facilitating, and designing. We believe these transitions cannot take place without establishing and nurturing social bonds over an extended period of time (in our case, 10-months and with nine sessions).

HCI designers can help families develop social bonds through different design methods, techniques, and strategies. Our work suggests that an effective approach for supporting the development of social bonds among participants is to first support parent-to-parent and childto-child bonds, then transition to parent-child social bonding. Xie et al. [64] recommended that separation from children affords older adults opportunities to design and elaborate with less stress and intimidation while also enabling them to commune over shared parental experiences. We agree with Xie et al. 's [64] points, but add that separation also allows for deeper conversation among the adults, particularly for sensitive and more mature topics on family interactions and struggles in parenting. In effect, social bonding took some amount of time during our design process. Children need time to work together with other children as well. By eliciting values in our initial sessions with parents alone, we enabled them to establish and build stronger social bonds with each other. Separate groups also allowed researchers to listen more closely to 
family needs and issues, which helped parents understand that we wanted them to contribute to design ideas, and not just facilitate their children's interactions. Over several months, as the parents bonded with each other, they developed a closer sense of community with the children of other families.

Changing Engagements and Social Bonds for Researchers Working With Parents and Children

Guha et al. [24] noted that adults often experience a learning curve as they transition to a full design partner. Our findings suggest this learning curve is especially difficult for parents, as they may have different motivations and perspectives about what it means to participate fully in co-design with their children.

First, parents might benefit more from facilitation by researchers than children do. While we observed that children generally adapted quickly to becoming design partners, their parents were more hesitant. For instance, Ms. Alexer explained she needed boundaries and more support in design: "I will say that every design thing I was like, I don't really know...Are they just looking for brainstorming ideas? Are there specific things that they are trying to figure out and they want to get, not consensus, but they want to get okay what do the majority of the people say? Or...It's just, sometimes it's very vague." Ms. Alexer's case was similar to other parents, and initially, we found that we needed to actively facilitate more group discussions with parents alone. We also had to offer more guidance to parents during design sessions, such as giving explicit reminders about the goals of the design and constant encouragement to try out new ideas. Second, we had to allow parents to join the design group when they felt comfortable. While we always encouraged every parent to participate in design sessions, parents did not always take up our invitation. For these parents, we focused our facilitator roles to work actively with their children, while gently reminding parents they could join in when they felt comfortable. We additionally encouraged children to feel free to invite and include their parents in design dialogue.

\section{Deeper Insight Into Family Relationships Over Time}

Finally, this study demonstrates how dedicated co-design work with families can offer us deeper insights on evolving family relationships. We do caution that timescales in PD cannot be measured in a singular unit. HCI researchers working with families spend a range of time, from several small workshops $[30,40,64]$, to several weeks and months $[28,42,57]$, and to multiple years $[33,63]$. However, in order to discern and support intergenerational family participants towards full co-design partnerships, we needed to examine time with the families in the micro (e.g., individual design sessions that lasted 90-minutes) and over time in the macro (e.g., multiple design sessions over a given number of months, and the frequency of those sessions). Therefore, we emphasize being sensitive to the evolution of the co-design relationships over various timescales. It is not simply the amount of time, but the quality of the interactions in the sessions that helps participants progress towards design partner engagements and social bonding.

Our 10-month, 9-design session experience did provide us more time to observe families in close contact. We believe an ancillary benefit to working closely in partnership with the families is that we began to not only gain insights into the design of our applications for the learning program, but we created an environment that allowed us to understand family dynamics over time. HCI research in PD with families already use interviews and home visits to better understand family relationships [28,33,40,42,57,63]. However, we suggest that observing families who are engaged in the process of co-design also reveals new insights into the relationships, tensions, and motivations of families.

We provide two examples of new insights. Initially, we thought that the design of our technologies would help parents actively talk to their children more about science. But we found that for some parents, supporting their children meant staying quiet in the background. As a result, we recognized that our designs need to account for a diverse range of ways that parents jointly engage with their children in media and technology, from quiet support to more active interactions [56]. Second, our observations of this group revealed that many parents must first be comfortable as a community before they can actively codesign with other children and advocate for another child's well-being. Before a community can interact effectively together, we found we must design support mechanisms into our science learning technologies that facilitate relationship building, not just between parent-child learning, but across family and community connections.

\section{CONCLUSION}

HCI researchers continuously seek ways to better understand and satisfy user needs. Our research into PD over an extended timeframe with families ( $\sim 10$ months, 9 sessions) indicates that these design partnerships can be complex and difficult, but will ultimately provide deeper insight into family interactions and technology design. As more researchers and designers consider families at the forefront in HCI, new PD methods and techniques will need to be considered, but we must also understand the engagements and social bonds that need to be facilitated for optimum insight into family needs.

\section{ACKNOWLEDGMENTS}

We would like to thank all of the children, parents, and community members who played an integral role in this project. We thank the anonymous reviewers and members of the HCIL and DUB groups for their feedback on this paper. This material is based upon work supported by the National Science Foundation under Grant No. 1441523. Any opinions, findings, and conclusions or recommendations expressed in this material are those of the author(s) and do not necessarily reflect the views of the National Science Foundation. 


\section{REFERENCES}

1. June Ahn, Tamara Clegg, Jason C. Yip, Elizabeth Bonsignore, Daniel Pauw, Michael Gubbels, Charley Lewites, \& Emily Rhodes. 2014. Seeing the unseen learner: Designing and using social media to recognize children's science dispositions in action. Learning Media \& Technology. http://dx.doi.org/10.1080/17439884.2014.964254

2. Morgan G. Ames, Janet Go, Joseph 'Jofish' Kaye, and Mirjana Spasojevic. 2010. Making love in the network closet: The benefits and work of family videochat. Proceedings of ACM Conference on Computer Supported Cooperative Work (CSCW'10), ACM, 145154. http://dl.acm.org/citation.cfm?id=1718946

3. Kaisa Aunola and Jari-Erik Nurmi. 2005. The role of parenting styles in children's problem behavior. Child Development 76, 6: 1144-1159.

4. Kaisa Aunola, Håkan Stattin, and Jari-Erik Nurmi. 2000. Parenting styles and adolescents' achievement strategies. Journal of Adolescence 23, 2: 205-222.

5. Brigid Barron, Caitlin Kennedy Martin, Lori Takeuchi, and Rachel Fithian. 2009. Parents as learning partners in the development of technological fluency. International Journal of Learning and Media 1, 2: 5577. http://doi.org/10.1162/ijlm.2009.0021

6. Diana Baumrind. 1991. The influence of parenting style on adolescent competence and substance use. The Journal of Early Adolescence 11, 1: 56-95.

7. S. Bødker, P. Ehn, D. Sjögren, and Y. Sundblad. 2000. Co-operative design - Perspectives on 20 years with "the Scandinavian IT Design Model." In Proc. of NordiCHI 2000, 1-9.

8. Tamara Clegg, Elizabeth Bonsignore, June Ahn, Jason C. Yip, Daniel Pauw, and Michael Gubbels. 2014. Capturing personal and social science: Technology for integrating the building blocks of disposition. In Proceedings of the Eleventh International Conference of the Learning Sciences.

9. A. Collins, D. Joseph, and K. Bielaczyc. 2004. Design research: Theoretical and methodological issues. The Journal of the Learning Sciences 13, 1: 15-42.

10. Christian M. Connell and Ronald J. Prinz. 2002. The impact of childcare and parent-child interactions on school readiness and social skills development for lowincome African American children. Journal of School Psychology 40, 2: 177-193.

11. J. W. Creswell. 1998. Qualitative Inquiry and Research Design: Choosing Among Five Traditions. Sage Publications, Thousand Oaks, CA.

12. Thomas Dalsgaard, Mikael B. Skov, Malthe Stougaard, and Bo Thomassen. 2006. Mediated intimacy in families: Understanding the relation between children and parents. Proceedings of the 2006 Conference on Interaction Design and Children, ACM, 145-152. http://dl.acm.org/citation.cfm?id=1139110

13. Thomas Dalsgaard, Mikael B. Skov, and Bo Ramsdahl Thomassen. 2007. eKISS: sharing experiences in families through a picture blog. Proceedings of the 21st British HCI Group Annual Conference on People and Computers, British Computer Society, 67-75. http://dl.acm.org/citation.cfm?id=1531304

14. Nancy Darling and Laurence Steinberg. 1993. Parenting style as context: An integrative model. Psychological Bulletin 113, 3: 487.

15. Eugene Lee Davids and Nicolette Vanessa Roman. 2014. A systematic review of the relationship between parenting styles and children's physical activity. African Journal for Physical, Health Education, Recreation and Dance 20: 228-246.

16. Francine DeHue, Catherine Bolman, and Trijntje Völlink. 2008. Cyberbullying: Youngsters' experiences and parental perception. CyberPsychology \& Behavior 11, 2: 217-223.

17. Allison Druin. 1999. Cooperative Inquiry: Developing new technologies for children with children. In Proceedings of the SIGCHI Conference on Human Factors in Computing Systems (CHI '99), 592-599.

18. Allison Druin. 2002. The role of children in the design of new technology. Behaviour and Information Technology 21, 1: 1-25.

19. Allison Druin, Benjamin B. Bederson, and Alex Quinn. 2009. Designing intergenerational mobile storytelling. Proceedings of the 8th International Conference on Interaction Design and Children, ACM, 325-328. http://dl.acm.org/citation.cfm?id=1551875

20. Batya Friedman. 1996. Value-sensitive design. Interactions 3, 6: 16-23.

21. Batya Friedman, Peter H. Kahn Jr, and Alan Borning. 2003. Value sensitive design: Theory and methods.

Retrieved September 10, 2015 from http://citeseerx.ist.psu.edu/viewdoc/summary?doi=10.1 .1.58.6046

22. James Paul Gee. 2000. Identity as an analytic lens for research in education. Review of Research in Education: 99-125.

23. Mona Leigh Guha, Allison Druin, Gene Chipman, Jerry Alan Fails, Sante Simms, and Allison Farber. 2004. Mixing ideas: A new technique for working with young children as design partners. In Proceedings of Interaction Design and Children, ACM, 35-42. http://doi.acm.org/10.1145/1017833.1017838

24. Mona Leigh Guha, Allison Druin, and Jerry Alan Fails 2013. Cooperative inquiry revisited: Reflections of the past and guidelines for the future of intergenerational co-design. International Journal of Child-Computer Interaction 1, 1: 14-23.

25. Shirley Brice Heath. 1983. Ways with Words: Language, Life and Work in Communities and Classrooms. Cambridge University Press.

26. Donell Holloway, Lelia Green, and Sonia Livingstone. 2013. Zero to Eight: Young Children and Their Internet use. EU Kids Online, LSE, London. Retrieved 
August 19, 2014 from

http://www.cci.edu.au/reports/ZerotoEight.pdf

27. K. Holtzblatt and S. Jones. 1993. Contextual inquiry: A participatory technique for system design. In Participatory Design: Principles and Practices, Douglas Schuler and Aki Namioka (eds.). CRC Press, 177-210.

28. Hilary Hutchinson, Wendy Mackay, Bo Westerlund, et al. 2003. Technology probes: Inspiring design for and with families. In Proceedings of the SIGCHI Conference on Human Factors in Computing Systems, 17-24. http://dl.acm.org/citation.cfm?id=642616

29. Sara Isola and Jerry Alan Fails. 2012. Family and design in the IDC and CHI communities. In Proceedings of the 11th International Conference on Interaction Design and Children, ACM, 40-49. http://dl.acm.org/citation.cfm?id=2307102

30. Nancy Kaplan and Yoram Chisik. 2005. Reading alone together: Creating sociable digital library books. In Proceedings of the 2005 Conference on Interaction Design and Children, ACM, 88-94. http://dl.acm.org/citation.cfm?id=1109552

31. F. Kensing and J. Blomberg. 1998. Participatory design: Issues and concerns. Computer Supported Cooperative Work (CSCW) 7, 3-4: 167-185.

32. Jean. Lave and E. Wenger. 1991. Situated Learning: Legitimate Peripheral Participation. Cambridge University Press, Cambridge, England.

33. Sinna Lindquist, Bo Westerlund, Yngve Sundblad, Helena Tobiasson, Michel Beaudouin-Lafon, and Wendy Mackay. 2007. Co-designing communication technology with and for families-Methods, experience, results and impact. In The Disappearing Computer, N. Streitz, A. Kameas and I. Mavrommati, (eds.), Springer, 99-119.

34. Sonia Livingstone. 2008. Taking risky opportunities in youthful content creation: teenagers' use of social networking sites for intimacy, privacy and selfexpression. New Media \& Society 10, 3: 393-411.

35. Sonia Livingstone and Magdalena Bober. 2006. Regulating the internet at home: contrasting the perspectives of children and parents. Digital generations: Children, Young People, and New Media: 93-113.

36. Gretchen Livingston. Less than half of U.S. kids today live in a "traditional" family | Pew Research Center. Retrieved September 11, 2015 from http://www.pewresearch.org/fact-tank/2014/12/22/lessthan-half-of-u-s-kids-today-live-in-a-traditionalfamily/

37. May O. Lwin, Andrea JS Stanaland, and Anthony D. Miyazaki. 2008. Protecting children's privacy online: How parental mediation strategies affect website safeguard effectiveness. Journal of Retailing 84, 2: 205-217.
38. S.B. Merriam. 2009. Qualitative Research: A Guide to Design and Implementation. John Wiley and Sons, San Francisco, CA.

39. Gustavo S. Mesch. 2009. Parental mediation, online activities, and cyberbullying. CyberPsychology \& Behavior 12, 4: 387-393.

40. Evelyn Milien, Camille Roux, and Caroline Golanski. 2004. Involving families in a design process. $P D C$, 187-190. Retrieved September 10, 2015 from http://rossy.ruc.dk/ojs/index.php/pdc/article/view/346

41. Meredith Minkler. 1994. Grandparents as parents. Ageing International 21, 1: 24-28.

42. Carman Neustaedter and A. J. Bernheim Brush. 2006. LINC-ing the family: the participatory design of an inkable family calendar. In Proceedings of the SIGCHI Conference on Human Factors in Computing Systems, ACM, 141-150.

http://dl.acm.org/citation.cfm?id=1124796

43. Elinor Ochs. 1993. Constructing social identity: A language socialization perspective. Research on language and Social Interaction 26, 3: 287-306.

44. Mark O'Hara. 2011. Young children's ICT experiences in the home: Some parental perspectives. Journal of Early Childhood Research 9, 3: 220-231. doi:10.1177/1476718X10389145

45. C. Pandya, J. Batalova, and M. McHugh. 2011. Limited English Proficient Individuals in the United States: Number, Share, Growth, and Linguistic Diversity. Migration Policy Institute, Washington, D.C.

46. Pew Research Center. 2013. A Survey of LGBT Americans: Attitudes, Experiences and Values in Changing Times. Pew Research Center.

47. Lydia Plowman and Joanna McPake. 2013. Seven myths about young children and technology. Childhood Education 89, 1: 27-33.

48. Lydia Plowman, Joanna McPake, and Christine Stephen. 2010. The technologisation of childhood? Young children and technology in the home. Children \& Society 24, 1: 63-74.

49. Lydia Plowman, Christine Stephen, and Joanna McPake. 2010. Supporting young children's learning with technology at home and in preschool. Research Papers in Education 25, 1: 93-113.

50. Martha Putallaz and Anne Hope Heflin. 1990. Parentchild interaction. In Peer Rejection in Childhood, Steven R. Asher and John D. Coie (eds.). CUP Archive, 189-216.

51. Hayes Raffle, Rafael Ballagas, Glenda Revelle, et al. 2010. Family story play: reading with young children (and Elmo) over a distance. In Proceedings of the SIGCHI Conference on Human Factors in Computing Systems, 1583-1592. http://dl.acm.org/citation.cfm?id=1753563

52. Diane Scott-Jones. 1995. Parent-child interactions and school achievement. In The Family-School Connection: Theory, Research, and Practice, Bruce A. 
Ryan, G.R. Adams, T.P. Gullotta, R.P. Weissberg and R.L. Hampton (eds.). SAGE, 75-107.

53. Shaheen Shariff. 2008. Cyber-bullying: Issues and Solutions for the School, the Classroom and the Home. Routledge.

54. Christopher Spera. 2005. A review of the relationship among parenting practices, parenting styles, and adolescent school achievement. Educational Psychology Review 17, 2: 125-146.

55. A. L Strauss and J. Corbin. 2007. Basics of Qualitative Research: Techniques and Procedures for Developing Grounded Theory, 3rd ed. SAGE Publications.

56. Lori Takeuchi and Reed Stevens. 2011. The New Coviewing: Designing for Learning Through Joint Media Engagement. The Joan Ganz Cooney Center at Sesame Workshop. Retrieved January 4, 2014 from http://www.joanganzcooneycenter.org/Reportsasc.html

57. Frank Vetere, Martin R. Gibbs, Jesper Kjeldskov, et al. 2005. Mediating intimacy: Designing technologies to support strong-tie relationships. In Proceedings of the SIGCHI Conference on Human factors in Computing Systems, 471-480. http://dl.acm.org/citation.cfm?id=1055038

58. Greg Walsh, Allison Druin, Mona Leigh Guha, et al. 2010. Layered elaboration: a new technique for codesign with children. In Proceedings of the SIGCHI Conference on Human Factors in Computing Systems, 1237-1240. http://doi.org/10.1145/1753326.1753512

59. Greg Walsh, Elizabeth Foss, Jason C. Yip, and Allison Druin. 2013. FACIT PD: Framework for analysis and creation of intergenerational techniques for participatory design. In Proceedings of the SIGCHI Conference on Human Factors in Computing Systems, 2893-2902.

60. Wendy Wang and Kim Parker. 2014. Record Share of Americans Have Never Married | Pew Research Center. Retrieved September 11, 2015 from http://www.pewsocialtrends.org/2014/09/24/recordshare-of-americans-have-never-married/
61. Ellen Wartella and Michael Robb. 2008. Historical and recurring concerns about children's use of the mass media. In The Handbook of Children, Media, and Development, S.L. Calvert and B.J. Wilson (eds.). John Wiley \& Sons, United Kingdom, 7-26.

62. Ellen Wartella, Vikki Rideout, Alexis Lauricella, and Sabrina Connell. 2013. Parenting in the Age of Digital Technology: A National Survey. Center on Media and Human Development, Northwestern University, Evanston, IL.

63. Bo Westerlund, Sinnna Lindqvist, Wendy Mackay, and Yngve Sundblad. 2003. Co-design methods for designing with and for families. In Proceedings of EAD 3.

64. Bo Xie, Allison Druin, Jerry Fails, et al. 2012. Connecting generations: Developing co-design methods for older adults and children. Behaviour \& Information Technology 31, 4: 413-423.

65. Svetlana Yarosh and Gregory D. Abowd. 2011. Mediated parent-child contact in work-separated families. In Proceedings of the SIGCHI Conference on Human Factors in Computing Systems, ACM, 11851194. http://dl.acm.org/citation.cfm?id=1979120

66. Svetlana Yarosh, Yee Chieh, and Gregory D. Abowd. 2009. Supporting parent-child communication in divorced families. International Journal of HumanComputer Studies 67, 2: 192-203.

67. Jason C. Yip, June Ahn, Tamara Clegg, Elizabeth Bonsignore, Daniel Pauw, and Michael Gubbels. 2014. "It helped me do my science." A case of designing social media technologies for children in science learning. In Proceedings of the 2014 Conference on Interaction Design and Children, ACM, 155-164

68. Jason C. Yip, Tamara Clegg, Elizabeth Bonsignore, Helene Gelderblom, Emily Rhodes, and Allison Druin. 2013. Brownies or Bags-of-Stuff? Domain expertise in Cooperative Inquiry with children. In Proceedings of the 2013 Conference on Interaction Design and Children, ACM, 201-210. 